Wright State University

CORE Scholar

Mechanical and Materials Engineering Faculty

Publications

Mechanical and Materials Engineering

7-1-2006

\title{
X-Ray Photoelectron Spectroscopic Studies of Dolomite Surfaces Exposed to Undersaturated and Supersaturated Aqueous Solutions
}

Xiaoming $\mathrm{Hu}$

Wright State University - Main Campus

Pratik Joshi

Wright State University - Main Campus

Sharmila M. Mukhopadhyay

Wright State University - Main Campus, sharmila.mukhopadhyay@wright.edu

Steven R. Higgins

Wright State University - Main Campus

Follow this and additional works at: https://corescholar.libraries.wright.edu/mme

Part of the Materials Science and Engineering Commons, and the Mechanical Engineering Commons

\section{Repository Citation}

Hu, X., Joshi, P., Mukhopadhyay, S. M., \& Higgins, S. R. (2006). X-Ray Photoelectron Spectroscopic Studies of Dolomite Surfaces Exposed to Undersaturated and Supersaturated Aqueous Solutions. Geochimica et Cosmochimica Acta, 70 (13), 3342-3350.

https://corescholar.libraries.wright.edu/mme/2

This Article is brought to you for free and open access by the Mechanical and Materials Engineering at CORE Scholar. It has been accepted for inclusion in Mechanical and Materials Engineering Faculty Publications by an authorized administrator of CORE Scholar. For more information, please contact library-corescholar@wright.edu. 


\title{
X-ray photoelectron spectroscopic studies of dolomite surfaces exposed to undersaturated and supersaturated aqueous solutions
}

\author{
Xiaoming $\mathrm{Hu}^{\text {a }}$, Pratik Joshi ${ }^{\mathrm{b}}$, Sharmila M. Mukhopadhyay ${ }^{\mathrm{b}}$, Steven R. Higgins ${ }^{\mathrm{a}, *}$ \\ a Department of Chemistry, Wright State University, Dayton, OH 45435, USA \\ ${ }^{\mathrm{b}}$ Department of Mechanical and Materials Engineering, Wright State University, Dayton, OH 45435, USA
}

Received 1 December 2005; accepted in revised form 24 April 2006

\begin{abstract}
Cleaved surfaces of dolomite were studied using ex-situ X-ray photoelectron spectroscopy (XPS) following exposure of the surfaces to various experimental conditions. Dolomite samples exposed to air, to a highly undersaturated solution $(0.1 \mathrm{M} \mathrm{NaCl}, \mathrm{pH}=9)$, and to solution with a supersaturation $(-\Delta \mu / \mathrm{kT})$ of $5.5(\mathrm{pH}=9)$ were investigated with semiquantitative methods of analysis to ascertain the degree of non-stoichiometry resulting at the dolomite surface from reactive conditions. It was found that the dolomite cleavage surface in undersaturated solution was not altered significantly from the stoichiometric surface termination. The composition of the cleaved surface after exposure to supersaturated solution, a surface known to have self-limiting growth characteristics under similar conditions, was found to be $\mathrm{Ca}^{2+}$ rich $\left(\mathrm{Ca}_{x} \mathrm{Mg}_{2}-x\left(\mathrm{CO}_{3}\right)_{2}, 1.7>x>1.3\right)$. The observations, while underscoring differences in hydration/dehydration kinetics of the two alkaline earth cations, suggest that achievement of equilibrium at dolomite-water interfaces may be subject to significant barriers from both undersaturated and supersaturated solutions.
\end{abstract}

(C) 2006 Elsevier Inc. All rights reserved.

\section{Introduction}

The chemical composition of solid-liquid interfaces is a subject of major significance in environmental geochemistry due to the impact of mineral-water interfacial reactions on the mobility and fate of aqueous solutes. The fundamental questions surrounding these types of systems are centered on the characterization of chemical and physical properties of boundaries that are often no more than a few atomic diameters in thickness. For example, to develop a reasonable model for the equilibria essential to the development of a charged mineral surface, an experimental method for characterizing the essential surface chemical entities and their relative abundances would be desired. Both direct and indirect approaches have provided a large volume of experimental data on the chemical and structural aspects of mineral-water interfaces (e.g., Hug and

\footnotetext{
${ }^{*}$ Corresponding author. Fax: +1 9377752479.

E-mail address: steven.higgins@wright.edu (S.R. Higgins).
}

Sulzberger, 1994; Knipe et al., 1995; Ainsworth et al., 1998; Brown et al., 1999; Fenter et al., 2000; Pokrovsky and Schott, 2002). These approaches, involving spectroscopic and analytical chemical tools, are generally applicable to any mineral class although specimen requirements in some techniques may preclude the study of many natural materials.

Mineral precipitation and growth in carbonate systems are of considerable importance in marine waters where supersaturated conditions in numerous solid carbonates prevail. Subsurface freshwater quality is linked to the kinetics and equilibria of carbonate-water interfaces, thereby underscoring the broad role of these minerals in aquatic environments. Dolomite $\left(\mathrm{CaMg}\left(\mathrm{CO}_{3}\right)_{2}\right)$ is geochemically relevant as it is a common sedimentary carbonate but is also important from a fundamental science perspective since the termination of its surface in aqueous solution may deviate significantly from the bulk solid and/or bulk solution stoichiometry. Epitaxial growth, or layer-by-layer growth, at the mineral-water interface has been demonstrated on various systems including homoepitaxial growth 
of calcite, barite, and celestite under supersaturated solutions (e.g., Higgins et al., 2000; Teng et al., 2000; Risthaus et al., 2001). However, dolomite does not form under similar low-temperature/low-pressure conditions (De Boer, 1977; Deelman, 1981; Hartman, 1982; Reeder, 1982; El-Mofty et al., 1989; Tribble et al., 1995; Brady et al., 1996; Arvidson and Mackenzie, 1997; Pokrovsky, 1998; Titiloye et al., 1998; De Leeuw, 2002) nor has epitaxial growth been observed in recent attempts on dolomite seed crystals (Higgins and $\mathrm{Hu}, 2005$ ). The surface $\mathrm{Ca} / \mathrm{Mg}$ ratio variability on dolomite surfaces may have implications in the tendency for formation (from supersaturated solution) of non-dolomite phases such as magnesian calcite, aragonite, and various carbonate hydrates (Pokrovsky, 1998).

The inhibition of dolomite growth at low temperatures has been explained by the large dehydration activation energy (and hence slow dehydration rate) of the $\mathrm{Mg}^{2+}\left(\mathrm{H}_{2} \mathrm{O}\right)_{6}$ complex, while dehydration of $\mathrm{Ca}^{2+}\left(\mathrm{H}_{2} \mathrm{O}\right)_{6}$ does not face comparable barriers (De Boer, 1977; Hartman, 1982). Another difficulty in dolomite growth is that a degree of disorder is more probable during growth due to the random occupation of $\mathrm{Mg}^{2+}$ sites by $\mathrm{Ca}^{2+}$ and vice versa, and thermochemical data (Nordstrom et al., 1990) indicate that disordered dolomite is only slightly less stable than the ordered phase.

The key to advancement of the understanding of dolomite-water interfaces entails the ability to measure surface composition. The adsorption of $\mathrm{Ca}^{2+}$ and $\mathrm{Mg}^{2+}$ to dolomite surfaces may favor one ion over the other via thermochemical controls, however, potentiometric and electrokinetic studies of dolomite powder suspensions by Pokrovsky et al. (1999) led to the modeling of this interface in which the affinities of $\mathrm{Mg}^{2+}$ and $\mathrm{Ca}^{2+}$ for surface carbonate sites were statistically similar when comparing the following ion exchange equilibria:

$$
\begin{aligned}
& >\mathrm{CO}_{3} \mathrm{H}+\mathrm{M}_{(\mathrm{aq})}^{2+} \Longleftrightarrow>\mathrm{CO}_{3} \mathrm{M}^{+}+\mathrm{H}_{(\mathrm{aq})}^{+} \\
& \mathrm{p} K(\mathrm{M}=\mathrm{Ca})=1.8 \pm 0.2 \\
& \mathrm{p} K(\mathrm{M}=\mathrm{Mg})=2.0 \pm 0.2 .
\end{aligned}
$$

Similar results were obtained by Brady et al. (1999) suggesting that adsorption of $\mathrm{Ca}^{2+}$ and $\mathrm{Mg}^{2+}$ from stoichiometric solution leads to a stoichiometric surface composition. The experimental data therefore suggest that there is no significant tendency for the dolomite surface to develop a non-stoichiometric composition in $\mathrm{Ca} / \mathrm{Mg}$ under near equilibrium conditions with respect to dolomite. In undersaturated solution however, more recent work by Pokrovsky and Schott (2001) indicated the tendency for $\mathrm{Ca}^{2+}$ to be released from the mineral surface approximately $10 \%$ faster than $\mathrm{Mg}^{2+}$ at $\mathrm{pH}=9$ within the first few hours of the reaction in a mixed-flow reactor. In batch reactor studies, the same preferential release of $\mathrm{Ca}^{2+}$ was observed in the first $100 \mathrm{~h}$ of reaction at $60^{\circ} \mathrm{C}$ in undersaturated, slightly alkaline aqueous solution (Tribble et al., 1995). Although stoichiometric dissolution obtains in the long-term as shown in Pokrovsky and Schott (2001), the initial imbalance implies a persistence of non-stoichiometric composition at the surface if bulk diffusion through the solid state is negligible. In addition to dissolution studies, attempts to synthesize dolomite in laboratory environments have led to the conclusion that low-temperature formation under well-controlled conditions is severely hindered.

A review of the formation of dolomite in laboratory experiments was provided by Tribble et al. (1995) and only a summary is provided herein. Most synthetic experiments yielded ordered dolomite from reaction of calcite (Lumsden et al., 1989; Sibley, 1990) and/or aragonite (Gaines, 1974; Katz and Matthews, 1977) under hydrothermal conditions. At temperatures below about $200{ }^{\circ} \mathrm{C}$, solid compositions close to stoichiometric in $\mathrm{Ca} / \mathrm{Mg}$ have been observed, but the degree of ordering observed was not complete (Graf and Goldsmith, 1956). Phase boundaries in the $\mathrm{CaCO}_{3}-\mathrm{MgCO}_{3}$ system in the presence of chloride solutions were determined at temperatures between 275 and $420^{\circ} \mathrm{C}$ (Rosenberg and Holland, 1964; Rosenberg et al., 1967). These studies indicated a shift in the stability field for dolomite toward higher $\mathrm{Mg}$ : Ca solution ratios as temperature decreased, but utilization of this trend to extrapolate to significantly lower temperatures is not justified.

While homoepitaxy of calcite was easily achieved, it has been found that the growth rate will be greatly reduced by the introduction of foreign divalent ions. In the case of $\mathrm{Mg}^{2+}$, it is generally believed that $\mathrm{Mg}^{2+}$ is an inhibitor for calcite growth (Davis et al., 2000; Zhang and Dawe, 2000; De Leeuw, 2002), and growth inhibition was suggested to result from enhanced mineral solubility through magnesium incorporation in the overgrown film. In a heteroepitaxial scenario (e.g., dolomite on calcite) however, lattice mismatch $(\sim 3.7 \%)$ between calcite $(a=0.641 \mathrm{~nm})$ and dolomite $(a=0.618 \mathrm{~nm})$ would lead to strain and defects, precluding formation of an epitaxial film. Key to resolving some of the surface chemical problems linked to the inhibition of dolomite formation is the study of well-characterized dolomite surfaces and their behavior under favorable conditions for dolomite growth. If these conditions tend to favor a non-stoichiometric surface composition (i.e., $\left[\mathrm{Ca}^{2+}\right] \neq\left[\mathrm{Mg}^{2+}\right]$ ), then the problem of dolomite formation may be more closely linked with solution composition in contrast to the formation of cation-ordered layers; a process which is arguably closely associated with surface reactions. In this work, X-ray Photoelectron Spectroscopy (XPS) is applied to dolomite cleavage surfaces exposed to various experimental conditions in an effort to constrain the range of $\mathrm{Ca} / \mathrm{Mg}$ ratios at the reacting interface.

\section{Experimental}

Optical grade dolomite (Ward's Natural Science Est. Inc.) was chosen as the seed for the experiments. X-ray diffraction characterization of this sample (Hu et al., 2005) indicated a single phase dolomite $(\mathrm{R} \overline{3})$ and identical lattice 
constants compared with the reported values in the literature. The single crystal sample was cleaved in air along its (104) plane, and pre-cleaned with de-ionized water (resistivity $>18 \mathrm{M} \Omega \mathrm{cm}$ ) to remove loose debris before the growth experiments.

Supersaturated solutions were prepared from high purity $\mathrm{CaCl}_{2}, \mathrm{MgCl}_{2}$, and $\mathrm{NaHCO}_{3}$ and undersaturated solutions were prepared from high purity $\mathrm{NaCl}$. The $\mathrm{pH}$ values for the solutions were adjusted to 9.0 by adding dilute $\mathrm{NaOH}$, and the ionic strength of all solutions was calculated to be about $0.11 \mathrm{M}$. The saturation state, defined as $\sigma=\ln \left(\mathrm{IAP} / K_{\mathrm{sp}}\right)$, was calculated using Visual MINTEQ. Here IAP is the ion activity product and $K_{\mathrm{sp}}$ is the solubility constant of dolomite $\left(\mathrm{p} K_{\mathrm{sp}}=17.09\right.$ at $25{ }^{\circ} \mathrm{C}$ ). After testing the growth rate with various supersaturations in an atomic force microscope (AFM), $\sigma=5.5$ for ordered dolomite was chosen for this study with equal $\mathrm{Ca}^{2+}$ and $\mathrm{Mg}^{2+}$ aqueous solution activities. Under this condition, step advancement was observed with AFM over a time scale of $1-2 \mathrm{~h}$. The experiments were performed in a beaker containing the single mineral grain sample and approximately $1 \mathrm{~L}$ of solution, agitated with a magnetic stir bar. For the samples studied with XPS, growth from supersaturated solution was allowed to continue for about $15 \mathrm{~h}$, whereas the undersaturation experiments were $1 \mathrm{~h}$ in duration. The samples were removed from the solutions with a tweezers. To prevent evaporative deposits from the solution remaining on the surface before XPS measurements, the samples were removed through hexane, which was on top of the growth solution. Due to its non-polar solvent character, hexane does not dissolve the substrate or any overgrown layers, but should aid in the displacement of the water film as the solid is drawn through the layer of hexane. The effectiveness of this process was verified by using an undersaturated solution $(0.1 \mathrm{M} \mathrm{NaCl}, \mathrm{pH}=9.0, \sigma \ll-3)$ with a layer of hexane between the solution and air. With the hexane layer in place, negligible to barely detectable $\mathrm{Na}$ $1 \mathrm{~s}$ and $\mathrm{Cl} 2 \mathrm{p}$ intensities were observed whereas earlier experiments performed without the hexane layer resulted in significant $\mathrm{Na}$ and $\mathrm{Cl}$ signals presumably from evaporation of a thick water layer that remained when the samples were directly removed into air.

XPS experiments were performed with a Kratos Axis Ultra equipped with an Al monochromatic X-ray source and a hemispherical electron spectrometer. The base vacuum was maintained in the low $10^{-10}$ torr range. Pass energy of the electron analyzer was set to $80 \mathrm{eV}$ and charge neutralization was applied during measurements. The energy scale was calibrated against surface adventitious carbon at $284.8 \mathrm{eV}$. In addition to the energy scale calibration, the binding energies of overlapping peaks were determined via peak fitting. Spectra were obtained both from surface normal electron emission and from a 60-degree electron emitting angle (from surface normal) to enhance surface sensitivity. The 60-degree emission data were used for quantitative comparisons.
The surface stoichiometry of the cleaved substrate was examined using hydrous powder form reference samples $\mathrm{CaCl}_{2}$ and $\mathrm{MgCl}_{2}$ (GFS Chemicals, purity $99.999 \%$ ). These calibration samples were baked under low vacuum at $110^{\circ} \mathrm{C}$ for over $12 \mathrm{~h}$ to remove most of the water, and the resulting dry powders were examined by XPS, the measurements for these samples were performed during the same day with the XPS operation parameters fixed during the period of these experiments. Electron intensities were averaged with multiple scans for all the photoemission peaks. The powder $\mathrm{CaCl}_{2}$ and $\mathrm{MgCl}_{2}$ results are shown in Figs. 1 and 2 for the $\mathrm{Ca} 3 \mathrm{~s}, \mathrm{Mg} 2 \mathrm{p}$, and $\mathrm{Cl} 2 \mathrm{p}$ photoemission peaks. The $\mathrm{Ca} 3 \mathrm{~s}$ and $\mathrm{Mg} 2 \mathrm{p}$ photoelectron peaks were used for instrument calibration due to their very similar electron inelastic mean free paths (IMFP, 32.6 $\AA$ for $\mathrm{Mg}$ $2 \mathrm{p}$ and $32.7 \AA$ for $\mathrm{Ca} 3 \mathrm{~s}$, respectively (Powell et al., 2005)), resulting from similar electron kinetic energies (1437 and $1442 \mathrm{eV}$ for $\mathrm{Mg} \mathrm{2p}$ and $\mathrm{Ca} \mathrm{3s}$, respectively). The differences in the attenuation of the electron emission intensities by the crystal surface were thus negligible. Integration of these peaks yielded integrated electron intensity values summarized in Table 1 . The peak areas give an instrument correction factor for $\mathrm{Mg} 2 \mathrm{p}$ normalized to $\mathrm{Ca}$ $3 \mathrm{~s}$, using $\mathrm{Cl} 2 \mathrm{p}$ as an internal standard, as:

$C_{\mathrm{Mg} 2 \mathrm{p} / \mathrm{Ca} 3 \mathrm{~s}}=\frac{\frac{I_{\mathrm{Mg} 2 \mathrm{p}}}{I_{\mathrm{Cl} 2 \mathrm{p}\left(\mathrm{MgCl}_{2}\right)}}}{\frac{I_{\mathrm{Ca} 3 \mathrm{~s}}}{I_{\mathrm{Cl} 2 \mathrm{p}\left(\mathrm{CaCl}_{2}\right)}}}=\frac{1331 / 13333}{925 / 15561}=1.7 \pm 0.1$.
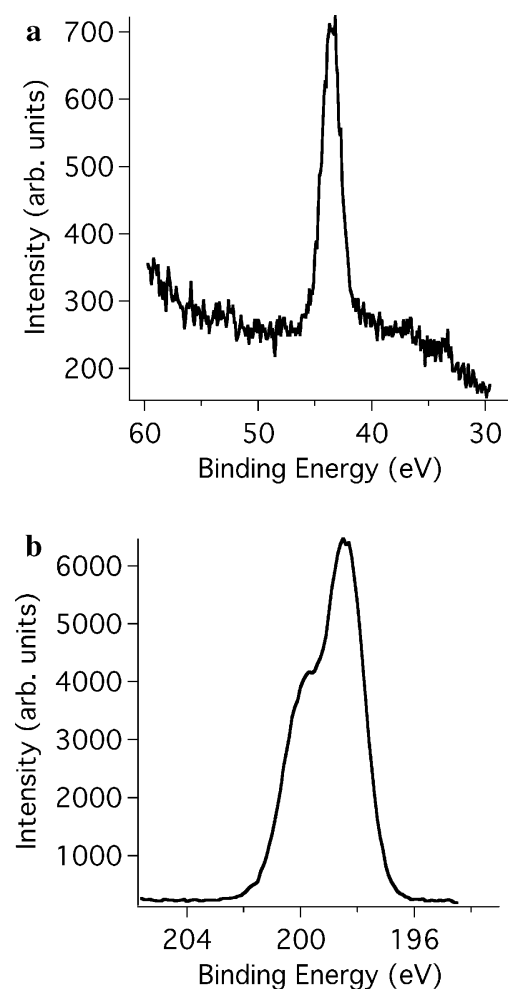

Fig. 1. (a) $\mathrm{Ca} 3 \mathrm{~s}$ photoemission peak from a dry $\mathrm{CaCl}_{2}$ powder reference sample and (b) $\mathrm{Cl} 2 \mathrm{p}$ peaks from the same sample. 

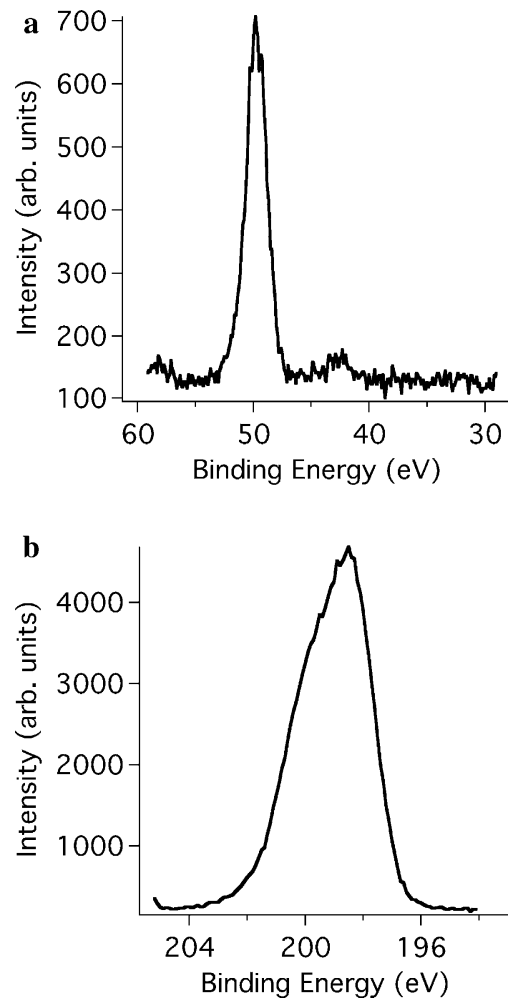

Fig. 2. (a) $\mathrm{Mg} 2 \mathrm{p}$ photoemission peak from a dry $\mathrm{MgCl}_{2}$ powder reference sample and (b) $\mathrm{Cl} 2 \mathrm{p}$ peaks from the same sample.

The uncertainty was evaluated from the uncertainties associated with the peak area measurements for $\mathrm{Mg} 2 \mathrm{p}(4.5 \%)$, $\mathrm{Ca} 3 \mathrm{~s}(6.6 \%)$, and $\mathrm{Cl} 2 \mathrm{p}\left(0.74 \%\right.$ for $\mathrm{MgCl}_{2}$ and $0.56 \%$ for $\mathrm{CaCl}_{2}$ ). It is worthwhile to compare this result here with the Scofield (1976) sensitivity factors calculated to be 0.334 for $\mathrm{Mg} 2 \mathrm{p}$ and 0.351 for $\mathrm{Ca} 3 \mathrm{~s}$ giving a ratio of $\mathrm{Mg} 2 \mathrm{p} / \mathrm{Ca} 3 \mathrm{~s}=0.952$, which differs significantly from the value obtained above, indicating that instrumental corrections for the spectrometer should be included rather than relying on Scofield factors for accurate surface analyses. A more detailed discussion on the applications of theoretical and experimental sensitivity factors for XPS quantitative analysis has been given by Seah et al. (2001).

\section{Results and discussion}

\subsection{Cleaved dolomite (104) surface}

A survey XPS scan for an as-cleaved dolomite with air exposure is shown in Fig. 3, where photoemission peaks including $\mathrm{Ca} 2 \mathrm{p}(347.1 \mathrm{eV}), \mathrm{Mg} 2 \mathrm{p}(50.3 \mathrm{eV}), \mathrm{O}$ 1s $(531.2 \mathrm{eV})$, and $\mathrm{C} 1 \mathrm{~s}(289.6 \mathrm{eV})$ were identified. While calcite has been studied extensively by XPS (Stipp et al., 1992; Baer and Moulder, 1993; Baer et al., 1993), to the authors' knowledge, no publication exists for the standard XPS spectra of dolomite. The most closely related work was a study by Gopinath et al. (2002) on polymorphic $\mathrm{CaCO}_{3}$ materials. Using photoionization cross-sections available in the literature and peak areas, they found that an aragonite sample (powder form, prepared by solution mixing) was carbonate terminated and a natural dolomite sample (powder form, Crystal Clays and Minerals, Rajasthan, India) was enriched with surface $\mathrm{Ca}$. It should be noted that the procedure used in Gopinath et al. (2002) utilized generalized sensitivity factors that may not be generally applicable to individual instruments as indicated in the last section.

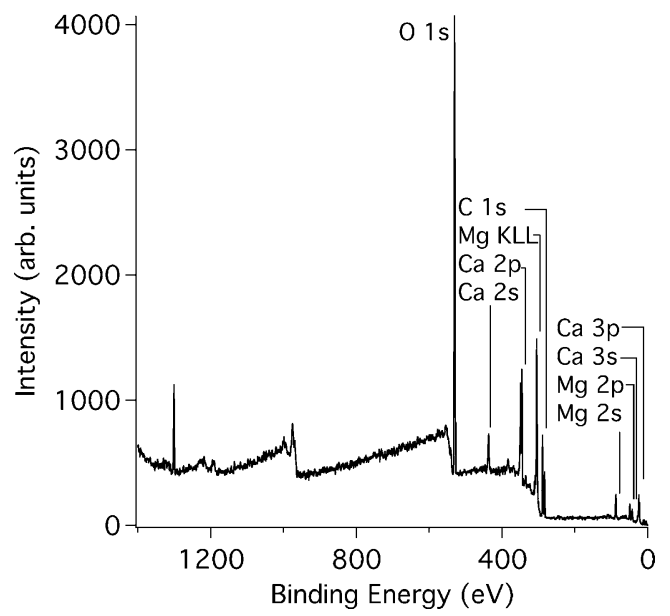

Fig. 3. XPS survey spectrum of the cleaved dolomite specimen.

Table 1

XPS peak areas from photoelectron spectra used in the quantitative analyses

\begin{tabular}{lllllll}
\hline & Cleaved \#1 & Cleaved \#2 & Undersaturated & Supersaturated & $\mathrm{CaCl}_{2}{ }^{\mathrm{a}}$ & $\mathrm{MgCl}_{2}{ }^{\mathrm{a}}$ \\
\hline $\mathrm{Ca} 2 \mathrm{p}$ & n.d. & $1.05( \pm 0.03) \times 10^{4 \mathrm{~d}}$ & $1.84( \pm 0.08) \times 10^{3 \mathrm{c}}$ & $2.9( \pm 0.1) \times 10^{3 \mathrm{c}}$ & n.d. & n.d. \\
$\mathrm{Ca} \mathrm{3s}$ & $7.9( \pm 0.5) \times 10^{2}$ & n.d. & n.d. & n.d. & $9.3( \pm 0.6) \times 10^{2}$ & n.d. \\
$\mathrm{Mg} 2 \mathrm{p}$ & $1.33( \pm 0.06) \times 10^{3}$ & $8.2( \pm 0.5) \times 10^{2 \mathrm{~d}}$ & $1.6( \pm 0.1) \times 10^{2 \mathrm{~b}}$ & $1.9( \pm 0.2) \times 10^{2 \mathrm{~b}}$ & n.d. & $1.33( \pm 0.06) \times 10^{3}$ \\
$\mathrm{Cl} 2 \mathrm{p}$ & N/A & N/A & n.d. & n.d. & $1.556( \pm 0.009) \times 10^{4}$ & $1.33( \pm 0.01) \times 10^{4}$ \\
$\mathrm{Ca} / \mathrm{Mg}$ & $0.59( \pm 0.05)$ & $12.8( \pm 0.8)$ & $12( \pm 1)$ & $15( \pm 1)$ & N/A & N/A \\
\hline
\end{tabular}

n.d., not determined; N/A, not applicable.

a $1.83 \mathrm{~s}$ count interval per data point.

b $2.61 \mathrm{~s}$ count interval per data point.

c 2.98 s count interval per data point.

d $0.75 \mathrm{~s}$ count interval per data point. The experiments labeled "Cleaved \#1" and "Cleaved \#2" were experiments performed on two separate dolomite specimens. The Cleaved \#1 sample was used in association with instrument calibration based on $\mathrm{CaCl}_{2}$ and $\mathrm{MgCl}_{2}$ reference materials. The experiments labeled "undersaturated" and "supersaturated" used separate dolomite specimens in each and these were only exposed to the $\sigma \ll-3(\mathrm{pH}=9.0)$ and $\sigma=5.5(\mathrm{pH}=9.0)$ solutions, respectively. 
For the cleaved dolomite substrate, the XPS spectrum containing both $\mathrm{Mg} 2 \mathrm{p}$ and $\mathrm{Ca} 3 \mathrm{~s}$ peaks is presented in Fig. 4. Taking the correction factor obtained in the last section into account, the surface region of the cleaved dolomite, exposed only to air, and based on peak areas, had a $\mathrm{Ca} / \mathrm{Mg}$ ratio of: $1.7 \times\left(\frac{792}{1338}\right)=1.0 \pm 0.1$ (with percentage errors of $4.8 \%$ for $\mathrm{Mg} 2 \mathrm{p}$ and $5.7 \%$ for $\mathrm{Ca} 3 \mathrm{~s}$ peak area determinations), indicating a close to stoichiometric surface. The $\mathrm{Mg}$ and $\mathrm{Ca}$ photoemission peaks from a cleaved sample will be used as a baseline for the comparison of surface $\mathrm{Ca} / \mathrm{Mg}$ ratio variations. By ratiometric comparison of the $\mathrm{Mg}$ and $\mathrm{Ca}$ photoemission peaks under study to those of the calibrated sample, unknown instrumental modifications to the relative sensitivity factors can be ignored in the quantification process.

\subsection{Dolomite surfaces exposed to aqueous solution}

Before comparing the $\mathrm{Ca}$ and $\mathrm{Mg}$ photoelectron intensities on the dolomite surfaces exposed to the aqueous solutions, the hexane extraction process was first tested for the quantitative removal of the near surface solution. In this experiment, a freshly cleaved sample was exposed to $0.1 \mathrm{M} \mathrm{NaCl}(\mathrm{pH}=9)$ solution for $\sim 2 \mathrm{~h}$ and was then removed through a layer of hexane. The XPS spectra revealed a barely detectable $\mathrm{Na} 1 \mathrm{~s}$ signal and no detectable $\mathrm{Cl} 2 \mathrm{p}$ signal. The Scofield (1976) sensitivity factor for $\mathrm{Na}$ $1 \mathrm{~s}$ is 8.52 and for $\mathrm{Cl} 2 \mathrm{p}$, is 2.29 , indicating that the $\mathrm{Cl} 2 \mathrm{p}$ signal was expected to be significantly weaker than that of the $\mathrm{Na} 1 \mathrm{~s}$ signal, and its absence in the spectrum was therefore expected.

Although the $\mathrm{Na}$ 1s signal level was only slightly above the background noise level, the ratio $\mathrm{Na} / \mathrm{Mg}$, determined by using the Scofield sensitivity factors (as an approximation) were estimated to be about $0.01 \pm 0.01$. This ratio may be used to further estimate that approximately $10 \%$ of the equivalent surface area occupied by $\mathrm{Mg}^{2+}$ was

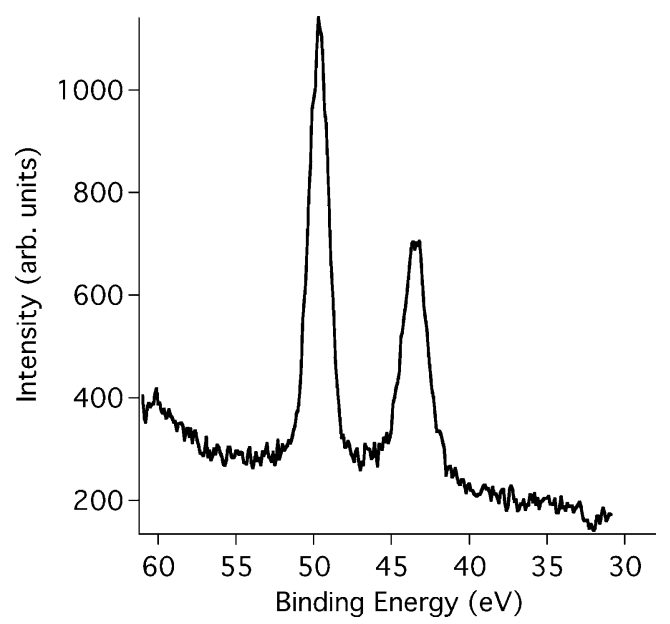

Fig. 4. $\mathrm{Mg} 2 \mathrm{p}$ and $\mathrm{Ca} 3 \mathrm{~s}$ photoemission peaks from a cleaved dolomite sample. Peak area analyses incorporating the instrument calibration, based on the peak areas from the reference materials, indicated a stoichiometric near surface composition. covered with $\mathrm{Na}^{+}$where the surface $\mathrm{Na} / \mathrm{Mg}$ ratio of 0.1 is based on the contribution to the $\mathrm{Mg} 2 \mathrm{p}$ electron intensity from roughly the top 10 layers from the bulk crystal whereas the $\mathrm{Na}$ ions are likely to be only physisorbed on the immediate surface and thus appear to be in relatively minor abundance on a peak area basis. By assuming this 0.1 monolayer of $\mathrm{Na}^{+}$(compared to a $\mathrm{Mg}^{2+}$ surface density of about $2.57 \times 10^{14}$ ions $/ \mathrm{cm}^{2}$ ) was deposited during the hexane pulling process and considering the $0.1 \mathrm{M} \mathrm{NaCl}$ solution used in the experiment, a solution layer with a thickness of about $4 \mathrm{~nm}$ was left on the surface, indicating the effectiveness of the hexane pulling process.

Upon exposure to supersaturated and undersaturated solutions, XPS spectra were collected from the dolomite surfaces and the results for $\mathrm{Ca} 2 \mathrm{p}$ and $\mathrm{Mg} 2 \mathrm{p}$ spectral regions are shown in Fig. 5. As can be seen from the peak area comparisons, taken from these spectra and summarized in Table 1, after dissolving in $0.1 \mathrm{M} \mathrm{NaCl}$, the surface showed a possibly $\mathrm{Mg}^{2+}$-rich termination $(\mathrm{Ca} / \mathrm{Mg}$ area
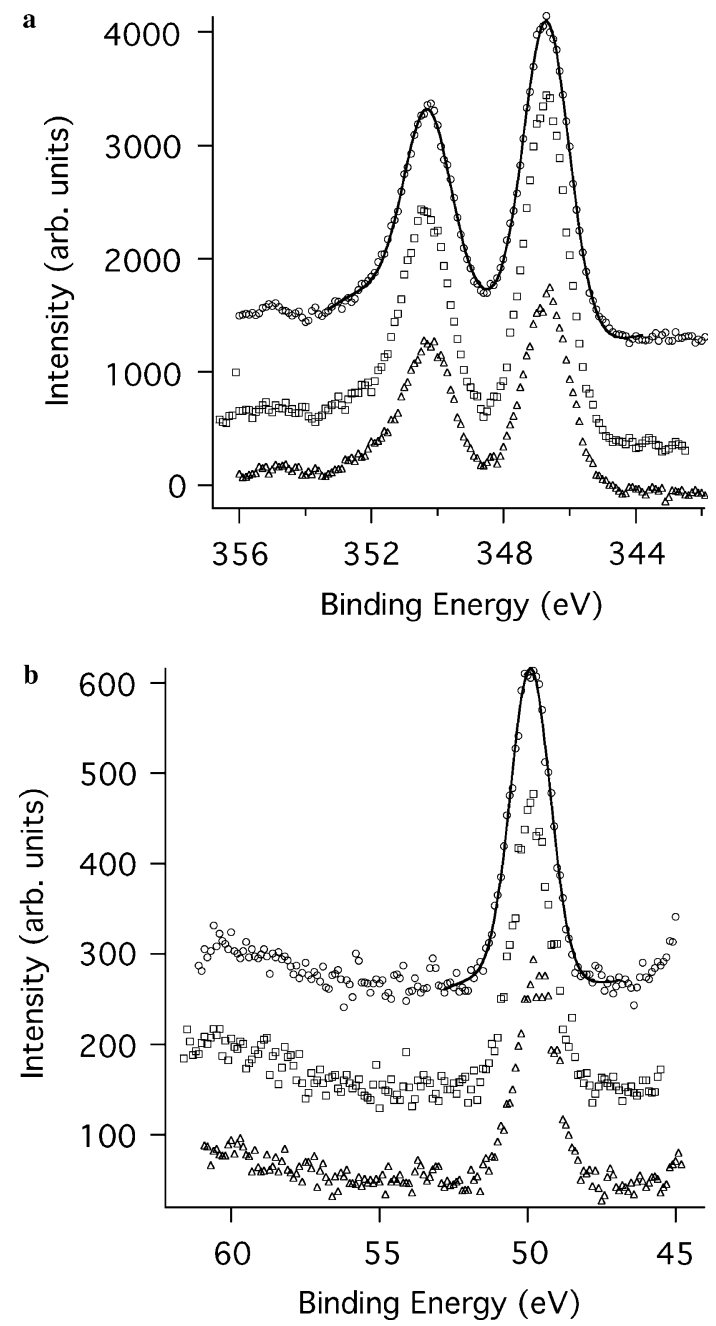

Fig. 5. (a) $\mathrm{Ca} 2 \mathrm{p}$ and (b) $\mathrm{Mg} 2 \mathrm{p}$ spectra obtained from samples exposed to air (circles), to supersaturated (squares), and to undersaturated (triangles) solutions. Example fitted curves to the experimental data are shown for the air-exposed samples. 
ratio $=12 \pm 1)$ compared to the as-cleaved surface $(\mathrm{Ca} / \mathrm{Mg}$ area ratio $=12.8 \pm 0.8$ ), while the sample exposed to supersaturated solution displayed a $\mathrm{Ca}^{2+}$-rich film $(\mathrm{Ca} /$ $\mathrm{Mg}$ area ratio $=15 \pm 1$ ), implying that $x>1$ for the overgrown $\mathrm{Ca}_{x} \mathrm{Mg}_{2-x}\left(\mathrm{CO}_{3}\right)_{2}$ layer.

The quantification of the surface stoichiometry with respect to $\mathrm{Ca}^{2+}$ and $\mathrm{Mg}^{2+}$ would require additional assumptions involving electron mean free paths in dolomite with correspondingly large uncertainties. Nevertheless, the majority of the photoelectron current arises typically from the topmost $1-10 \mathrm{~nm}$ of material, suggesting that detection of compositional differences from a single molecular layer ( $\sim 0.3 \mathrm{~nm}$ thick) would require a large change in composition from this surface to the underlying bulk solid. The overgrown monolayer produced a very significant change of $+17 \%$ in the $\mathrm{Ca} / \mathrm{Mg}$ XPS area ratio indicating that the surface $\mathrm{Ca}$ enrichment was likely considerably larger. If contributions to the photoelectron current were assumed to be significant from the topmost four layers (i.e., an effective electron escape depth of about $1.2 \mathrm{~nm}$ ), the surface layer would need to have an approximate composition of $\mathrm{Ca}_{1.3} \mathrm{Mg}_{0.7}\left(\mathrm{CO}_{3}\right)_{2}$ to account for the increased $\mathrm{Ca} 2 \mathrm{p}$ intensity relative to $\mathrm{Mg} 2 \mathrm{p}$. If the escape depth was closer to $10 \mathrm{~nm}$, a surface composition of approximately $\mathrm{Ca}_{1.7} \mathrm{Mg}_{0}$. ${ }_{3}\left(\mathrm{CO}_{3}\right)_{2}$ would be necessary to generate the observed signal changes. Therefore, a reasonable constraint for the surface composition in the growth experiments limits the $\mathrm{Ca} / \mathrm{Mg}$ concentration ratio to within the range $2<\mathrm{Ca} / \mathrm{Mg}<6$. For the dissolution experiments, because the observed signal changes were not statistically significant, the surface composition would likely fall in the range $0.5<\mathrm{Ca} /$ $\mathrm{Mg}<1$.

Surface carbon contamination due to air exposure may have attenuated the photoemission signal intensities due to the difference in the electron IMFP of Ca $2 p(27.2 \AA)$ and $\mathrm{Mg} 2 \mathrm{p}$ (32.6 $\AA$ ) (Powell et al., 2005). It was found that the samples exposed to aqueous solutions and hexane showed higher levels of surface carbon than the cleaved surface. Considering that the $\mathrm{Mg} 2 \mathrm{p}$ photoelectrons have a higher electron kinetic energy $(\mathrm{KE}=1437 \mathrm{eV})$ and larger IMFP than those of the $\mathrm{Ca} 2 \mathrm{p}$ peak $(\mathrm{KE}=1140 \mathrm{eV})$, it is expected that signals from the $\mathrm{Ca} 2 \mathrm{p}$ peak will be attenuated more than that of the $\mathrm{Mg} 2 \mathrm{p}$ peak. This means that the detected $\mathrm{Ca} 2 \mathrm{p}$ signal may have been underestimated, and a correction, if necessary, should be made so that the results are further shifted to the Ca-rich direction. While this does not change the conclusion that the surface exposed to the supersaturated solution became $\mathrm{Ca}$ rich, the $\mathrm{Mg}$ enrichment for the sample exposed to the undersaturated solution may be a result of the underestimation of $\mathrm{Ca} 2 \mathrm{p}$ intensity. Quantification of the surface contamination layer thickness and its effects on the detected $\mathrm{Ca} 2 \mathrm{p}$ and $\mathrm{Mg} 2 \mathrm{p}$ signals is possible, but would involve careful calibration of the instrument against all the contamination elements (mainly $\mathrm{C}$ and $\mathrm{O}$ ) and simulations of the XPS spectra (e.g., Smekal et al., 2005). These additional quantitative problems are beyond the scope of this investigation.
Earlier work on the microtopographic and lateral force characteristics of dolomite surfaces in similar solutions led to a number of noteworthy observations (Higgins and $\mathrm{Hu}$, 2005). Fig. 6 shows in situ AFM images taken from these previous studies. Figs. 6a and b display the typical dolomite surface topography and lateral deflection signals observed in highly undersaturated solution, indicating the ubiquitous presence of monolayer etch pits and the tendency for these surfaces to dissolve by removal of ions from the step edges. Figs. $6 \mathrm{c}$ and d contain both topographic and lateral deflection images taken during exposure of the dolomite cleavage surface to supersaturated solution. Crystal growth was observed to occur via advance of monolayer step edges, but the growth process was found to be effectively limited to precipitation of one layer; subsequent layer precipitation was considerably hindered. The clear contrast in the lateral deflection image (Fig. 6d) indicated a difference in the properties of the tip microcontact with the native dolomite surface in comparison to the monolayer-covered regions. The lateral deflection contrast could arise from differences in the tip-surface contact area, originating from contact deformation or from differences in chemical forces, changing the effective normal load. Unfortunately, there is no reliable model that would permit determination of the monolayer composition from the lateral deflection signal. The XPS measurements reported here permit reasonable constraints to be placed on the surface composition in terms of the divalent cations.

\subsection{Surface Mg enrichment in undersaturated solution}

The tendency toward $\mathrm{Mg}^{2+}$-rich termination for dolomite in an undersaturated environment, discussed in the introduction from work by Pokrovsky and Schott (2001) and Tribble et al. (1995), was also observed by El-Mofty et al. (1989). They found that at low solid-to-liquid ratios and for short time intervals, which is equivalent to the dolomite dissolution studies in this paper, preferential dissolution of $\mathrm{Ca}$ occurred leading to a $\mathrm{Mg}$-enriched dolomite surface. The experimental data reported in this work are not conclusive as to the presence of a $\mathrm{Mg}$-rich surface upon reaction in undersaturated solution.

The Mg-enriched surface that developed in the other dolomite studies, perhaps expected on the basis of general kinetic arguments related to hydration of $\mathrm{Mg}^{2+}$ and $\mathrm{Ca}^{2+}$, is surprising nonetheless because dissolution at step edges presumably is a stoichiometric process. If only the step edges were enriched in $\mathrm{Mg}^{2+}$ (a plausible consequence of detachment-limited dissolution from these sites), then considering that step edges comprise roughly $0.3 \%$ of the surface sites, and definitely, as an upper bound, no more than $1 \%$ of the available surface sites, the relative change in $\mathrm{Ca} 2 \mathrm{p}$ and $\mathrm{Mg}$ $2 p$ electron intensities would be negligible, a prediction that is consistent with the data reported herein. If, however, detachment of or hydration of $\mathrm{Mg}^{2+}$ sorbed to the terrace sites was relatively slow (i.e., the rate-determining step, per se), considerable surface enrichment is reasonable. These 

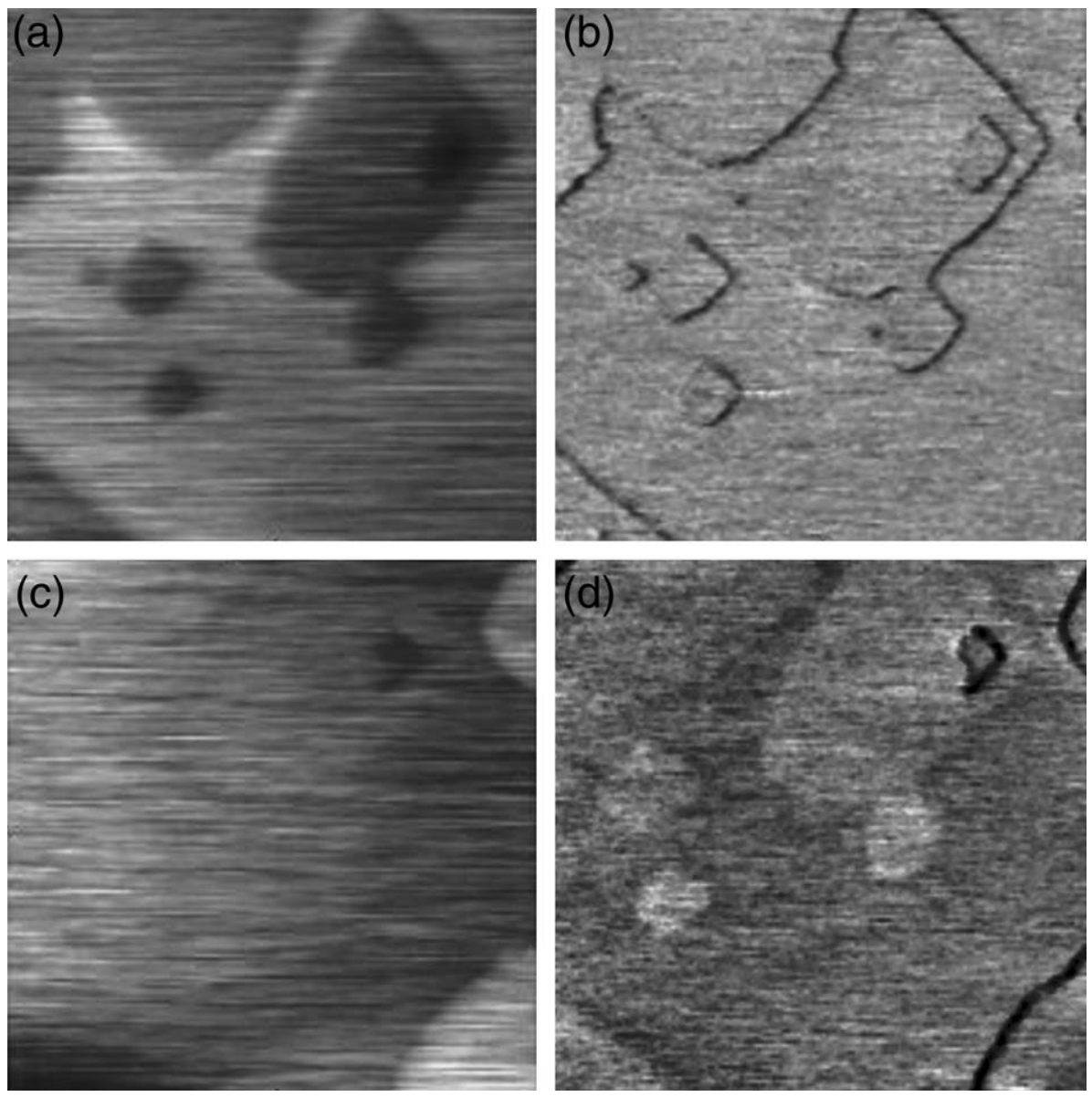

Fig. 6. Topographic (left) and lateral deflection (right) images $(645 \mathrm{~nm} \times 645 \mathrm{~nm})$ of (a and b) a dolomite surface exposed to undersaturated solution, revealing the characteristic rhombic shaped monolayer etch pits, and (c and d) approximately 10 min following introduction of supersaturated solution $(\sigma=5.3)$. Experimental results described previously in Higgins and $\mathrm{Hu}(2005)$.

sorbed ions are not likely to be visible in the AFM because the lateral forces in an AFM experiment could far exceed the strength of the metal-to-surface interaction, permitting the tip to readily move these ions about. A second plausible pathway for generating a Mg-enriched surface during dissolution involves the detachment of ions from within the terraces, forming terrace vacancies, in contrast to the previous concept of detachment of adsorbed ions. The ignorance of vacancies may lead to incorrect conclusions regarding the mechanisms by which surface chemistry is influenced by dissolution processes. Finally, because the prior studies were done on granular or powdered dolomite specimens, it is reasonable that surface enrichment of $\mathrm{Mg}$ on dolomite occurs on surfaces other than (104). Nevertheless, the lack of conclusive surface chemical data renders speculative further discussion of the mechanism for $\mathrm{Mg}$ surface enrichment observed in prior work, but additional studies using highresolution X-ray reflectivity could provide surface structural evidence to test these hypothetical scenarios.

\subsection{Surface Ca enrichment in supersaturated solution}

The experimental data suggest significant surface enrichment in $\mathrm{Ca}^{2+}$ relative to $\mathrm{Mg}^{2+}$ when cleaved samples were exposed to supersaturated solution. This result is in agreement with predictions based on extrapolation of high-temperature experimental data from Rosenberg et al. (1967) and Rosenberg and Holland (1964) where stoichiometric dolomite would require significant excess $\mathrm{Mg}^{2+}$ in solution at low temperatures. By using atomistic simulations, Titiloye et al. (1998) calculated the segregation energies for $\mathrm{Ca}^{2+}$ and $\mathrm{Mg}^{2+}$ on various dolomite surfaces. They found that $\mathrm{Ca}^{2+}$ prefers to segregate to the surface while the $\mathrm{Mg}^{2+}$ prefers to dissolve into the bulk solid when simulations were performed on the prismatic $\{100\}$ and $\{110\}$ surfaces. This result provides further thermodynamic evidence for a driving force favoring the formation of magnesian calcite through phase segregation at the surface. In Titiloye et al. (1998), the stability of the $\{104\}$ surfaces was relatively low compared to $\{100\}$ and $\{110\}$, and therefore, segregation computations were not performed on the cleavage plane. Likewise, comparison of the observed $\mathrm{Ca}^{2+}$ enrichment on the (104) surface with theoretical predictions for $\mathrm{Ca}^{2+}$ enrichment on the prismatic faces is not entirely appropriate. In addition, the Titiloye et al. studies did not include the effects of $\mathrm{H}_{2} \mathrm{O}$ and its ion association, which may also have played an important role in the differential incorporation of $\mathrm{Ca}^{2+}$ and $\mathrm{Mg}^{2+}$ in the experiments. While 
the experimental results in this paper showed a $\mathrm{Ca}^{2+}$-rich surface for dolomite growth, segregation of $\mathrm{Mg}^{2+}$ into the bulk cannot be confirmed in these experiments. The difficulty in $\mathrm{Mg}^{2+}$ substituting for $\mathrm{Ca}^{2+}$ in the bulk arises from the expected slow solid-state diffusion rate at room temperature.

To summarize the observations and the explanations, the as-cleaved dolomite (104) surface showed stoichiometric termination for $\mathrm{Ca}^{2+}$ and $\mathrm{Mg}^{2+}$. Following dissolution in $0.1 \mathrm{M}$ $\mathrm{NaCl}$ solution for $1 \mathrm{~h}$, the surface remained stoichiometric, if not slightly $\mathrm{Mg}^{2+}$ rich. The $\mathrm{Ca}^{2+}$ rich growth from supersaturated solution suggests that $\mathrm{Ca}^{2+}$ incorporates and is dehydrated in the film much faster than $\mathrm{Mg}^{2+} . \mathrm{Ca}^{2+}$ will occupy many $\mathrm{Mg}^{2+}$ sites expected for ordered dolomite, and as a result, the monolayer will be disordered, strained and/or highly defective in a crystalline framework of the dolomite substrate, hence only short range-ordered structures are expected, despite the highly ordered substrate. As the new template is more strained than the substrate, further growth of subsequent layers would result in a poorer quality layer than the first layer, and hence, a drastic increase in the film solubility. This will effectively lead to the inhibition of any additional growth. Evidence to support this hypothesis was provided from earlier observations that the first layer even dissolved in supersaturated solutions for ordered dolomite $(\sigma=2.3)$ (Hu et al., 2005).

\section{Conclusions}

Ex situ XPS studies revealed non-stoichiometric, nearsurface composition of dolomite samples following exposure to undersaturated and supersatured solutions. The overgrowth composition was definitively $\mathrm{Ca}$ rich $(2<\mathrm{Ca} /$ $\mathrm{Mg}<6)$ based on the comparison of electron intensities for $\mathrm{Mg} 2 \mathrm{p}$ and $\mathrm{Ca} 2 \mathrm{p}$ photoelectron peaks whereas on dissolved dolomite, the surface chemistry data were inconclusive leaving the possibility of a stoichiometric or slightly Mg-rich $(0.5<\mathrm{Ca} / \mathrm{Mg}<1)$ surface termination. Enrichment of surface $\mathrm{Ca}^{2+}$ composition from stoichiometric supersaturated solutions was likely due to the relatively slow dehydration kinetics of $\mathrm{Mg}\left(\mathrm{H}_{2} \mathrm{O}\right)_{6}{ }^{2+}$ in comparison to that of $\mathrm{Ca}\left(\mathrm{H}_{2} \mathrm{O}\right)_{6}{ }^{2+}$. These results were also consistent with low-temperature nucleation experiments where magnesian calcite precipitates from solution more readily than dolomite. Evidently, the presumed ordered surface provided by the cleaved dolomite did not sufficiently control the attachment locations for ions from solution. Because these studies were quite far from equilibrium and the overgrowth properties (defect density and composition, primarily) are likely to depend on the supersaturation, a method for quantifying surface defects or domain textures could lead to a clearer understanding of the problem of low-temperature dolomite formation. Additional studies, particularly those providing in situ interface compositional and structural data, on the rate-governing processes in dolomite dissolution and precipitation are necessary to further test the conclusions herein.

\section{Acknowledgments}

The authors gratefully acknowledge the support of this work by the US Department of Energy, Office of Basic Energy Sciences ( $\mathrm{SRH})$, and the donors of the American Chemical Society, Petroleum Research Fund (SRH), and a grant from the Wright State Research Challenge Program (SRH and SMM). Dr. William Feld from Wright State University is also acknowledged for the $\mathrm{CaCl}_{2}$ and $\mathrm{MgCl}_{2}$ powder sample preparations and assistance with the XPS from Vamsee K. Chintamaneni of Wright State University is also acknowledged. Comments from Don Baer and two anonymous reviewers contributed to improvements on the original manuscript.

\section{Associate editor: Dimitri A. Sverjensky}

\section{References}

Ainsworth, C.C., Friedrich, D.M., Gassman, P.L., Wang, Z., Joly, A.G., 1998. Characterization of salicylate-alumina surface complexes by polarized fluorescence spectroscopy. Geochim. Cosmochim. Acta 62 (4), 595-612.

Arvidson, R.S., Mackenzie, F.T., 1997. Tentative kinetic model for dolomite precipitation rate and its application to dolomite distribution. Aquatic Geochem. 2, 273-298.

Baer, D.R., Marmorstein, A.M., Williford, R.E., Blanchard, D.L., 1993. Comparison spectra for calcite by XPS. Surf. Sci. Spectra 1, 80-86.

Baer, D.R., Moulder, J.F., 1993. High resolution XPS spectrum of calcite (CaCO3). Surf. Sci. Spectra 2, 1-7.

Brady, P.V., Krumhansl, J.L., Papenguth, H.W., 1996. Surface complexation clues to dolomite growth. Geochim. Cosmochim. Acta 60, $727-731$.

Brady, P.V., Papenguth, H.W., Kelly, J.W., 1999. Metal sorption to dolomite surfaces. Applied Geochem. 14, 569-579.

Brown, G.E., Henrich, V.E., Casey, W.H., Clark, D.L., Eggleston, C., Felmy, A., Goodman, D.W., Gratzel, M., Maciel, G., McCarthy, M.I., Nealson, K.H., Sverjensky, D.A., Toney, M.F., Zachara, J.M., 1999. Metal oxide surfaces and their interactions with aqueous solutions and microbial organisms. Chem. Rev. 99 (1), 77-174.

Davis, K.J., Dove, P.M., DeYoreo, J.J., 2000. The role of $\mathrm{Mg}^{2+}$ as an impurity in calcite growth. Science 290, 1134-1137.

De Boer, R.B., 1977. Stability of Mg-Ca carbonates. Geochim. Cosmochim. Acta 41, 265-270.

De Leeuw, N.H., 2002. Surface structures, stabilities, and growth of magnesian calcite: a computational investigation from the perspective of dolomite formation. Am. Mineral. 87, 679-689.

Deelman, J.C., 1981. Studies on irreversible geochemical reactions. No. 5. Dolomite formation: why thermodynamics failed. Neues Jahrbuch fuer Mineralogie, Abhandlungen 141, 30-58.

El-Mofty, S.E., Somasundaran, P., Viswanathan, K.V., 1989. Ca/Mg enrichment of dolomite surface in aqueous solutions: solid/liquid ratio and mixing time effects. Miner. Metall. Process. 6, 96-99.

Fenter, P., Geissbuhler, P., DiMasi, E., Srajer, G., Sorensen, L.B., Sturchio, N.C., 2000. Surface speciation of calcite observed in situ by high-resolution X-ray reflectivity. Geochim. Cosmochim. Acta 64 (7), 1221-1228.

Gaines, A.M., 1974. Protodolomite synthesis at $100^{\circ} \mathrm{C}$ and atmospheric pressure. Science 183, 178-182.

Gopinath, C.S., Hegde, S.G., Ramaswamy, A.V., Mahapatra, S., 2002. Photoemission studies of polymorphic $\mathrm{CaCO}_{3}$ materials. Mater. Res. Bull. 37, 1323-1332.

Graf, D.L., Goldsmith, J.R., 1956. Some hydrothermal syntheses of dolomite and protodolomite. J. Geol. 64, 173-186. 
Hartman, P., 1982. On the growth of dolomite and kaolinite crystals. Neues jahrbuch fuer Mineralogie, Monatshefte 2, 84-92.

Higgins, S.R., Bosbach, D., Eggleston, C.M., Knauss, K.G., 2000. Kink dynamics and step growth on barium sulfate (001): a hydrothermal scanning probe microscopy study. J. Phys. Chem. B 104 (30), 69786982.

Higgins, S.R., Hu, X., 2005. Self-limiting growth on dolomite: experimental observations with in-situ atomic force microscopy. Geochim. Cosmochim. Acta 69, 2085-2094.

Hu, X., Grossie, D.A., Higgins, S.R., 2005. Growth and dissolution kinetics at the dolomite-water interface: an in-situ scanning probe microscopy study. Am. Mineral. 90, 963-968.

Hug, S.J., Sulzberger, B., 1994. In-situ Fourier transform infrared spectroscopic evidence for the formation of several different surface complexes of oxalate on $\mathrm{TiO}_{2}$ in the aqueous phase. Langmuir 10, 3587-3597.

Katz, A., Matthews, A., 1977. The dolomitization of $\mathrm{CaCO}_{3}$, an experimental study at 252-295 degrees C. Geochim. Cosmochim. Acta 41 (2), 297-308.

Knipe, S.W., Mycroft, J.R., Pratt, A.R., Nesbitt, H.W., Bancroft, G.M., 1995. X-ray photoelectron spectroscopic study of the water adsorption on iron sulphide minerals. Geochim. Cosmochim. Acta 59 (6), 1079-1090.

Lumsden, D.N., Shipe, L.G., Lloyd, R.V., 1989. Mineralogy and Mn geochemistry of laboratory-synthesized dolomite. Geochim. Cosmochim. Acta 53, 2325-2329.

Nordstrom, D.K., Plummer, L.N., Langmuir, D., Busenberg, E., May, H.M., 1990. Revised chemical equilibrium data for major watermineral reactions and their limitations. In: Melchior, D.C., Bassett, R.L. (Eds.), Chemical Modelling of Aqueous Systems II, vol. 416. American Chemical Society, pp. 398-413.

Pokrovsky, O.S., 1998. Precipitation of calcium and magnesium carbonates from homogeneous supersaturated solutions. J. Cryst. Growth 186, 233-239.

Pokrovsky, O.S., Schott, J., 2001. Kinetics and mechanism of dolomite dissolution in neutral to alkaline solutions revisited. Am. J. Sci. 301 (7), 597-626.

Pokrovsky, O.S., Schott, J., 2002. Surface chemistry and dissolution kinetics of divalent metal carbonates. Environ. Sci. Tech. 36 (3), 426-432.

Pokrovsky, O.S., Schott, J., Thomas, F., 1999. Dolomite surface speciation and reactivity in aquatic systems. Geochim. Cosmochim. Acta 63 (19/20), 3133-3143.
Powell, C.J., Jablonski, A., Salvat, F., 2005. NIST databases with electron elastic-scattering cross sections, inelastic mean free paths, and effective attenuation lengths. Surf. Interface Anal. 37, 1068-1071.

Reeder, R.J., 1982. Crystal growth effects in sedimentary carbonate minerals. Estudios Geol. 38, 179-183.

Risthaus, P., Bosbach, D., Becker, U., Putnis, A., 2001. Barite scale formation and dissolution at high ionic strength studied with Atomic Force Microscopy. Colloids Surf. A 191/3, 201-214.

Rosenberg, P.E., Burt, D.M., Holland, H.D., 1967. Calcite-dolomitemagnesite stability relations in solutions: the effect of ionic strength. Geochim. Cosmochim. Acta 31, 391-396.

Rosenberg, P.E., Holland, H.D., 1964. Calcite-dolomite-magnesite stability relations in solutions at elevated temperatures. Science $\mathbf{1 4 5}$, 700-701.

Scofield, J.H., 1976. Hartree-Slater subshell photoionization cross-sections at 1254 and 1487 eV. J. Electron Spectrosc. 8, 129-137.

Seah, M.P., Gilmore, I.S., Spencer, S.J., 2001. Quantitative XPS I. Analysis of X-ray photoelectron intensities from elemental data in a digital photoelectron database. J. Electron Spectrosc. 120, 93-111.

Sibley, D.F., 1990. Unstable to stable transformations during dolomitization. J. Geol. 98, 739-748.

Stipp, S.L., Hochella Jr., M.F., Parks, G.A., Leckie, J.O., 1992. $\mathrm{Cd}^{2+}$ uptake by calcite, solid-state diffusion, and the formation of solidsolution: interface processes observed with near-surface sensitive techniques (XPS, LEED, and AES). Geochim. Cosmochim. Acta 56, 1941-1954.

Smekal, W., Werner, W.S.M., Powell, C.J., 2005. Simulation of electron spectra for surface analysis (SESSA): a novel software tool for quantitative Auger-electron spectroscopy and X-ray photoelectron spectroscopy. Surf. Interface Anal. 37, 1059-1067.

Teng, H.H., Dove, P.M., De Yoreo, J.J., 2000. Kinetics of calcite growth: surface processes and relationships to macroscopic rate laws. Geochim. Cosmochim. Acta 64 (13), 2255-2266.

Titiloye, J.O., De Leeuw, N.H., Parker, S.C., 1998. Atomistic simulation of the differences between calcite and dolomite surfaces. Geochim. Cosmochim. Acta 62, 2637-2641.

Tribble, J.S., Arvidson, R.S., Lane III, M., Mackenzie, F.T., 1995. Crystal chemistry, and thermodynamic and kinetic properties of calcite, dolomite, apatite, and biogenic silica: applications to petrologic problems. Sediment. Geol. 95 (1-2), 11-37.

Zhang, Y., Dawe, R.A., 2000. Influence of $\mathrm{Mg}^{2+}$ on the kinetics of calcite precipitation and calcite crystal morphology. Chem. Geol. 163, 129-138. 